\title{
CAPITAL CULTURAL E EDUCAÇÃO
}

\author{
Reginaldo Oliveira Guimarães ${ }^{1}$
}

RESUMO: Este artigo tem o objetivo de promover uma breve reflexão sobre os argumentos expostos por Bourdieu sobre o capital cultural e sua contribuição no processo educativo onde ele explica a diferença entre educação formal escolar e a educação familiar e como este segundo processo pode contribuir com a educação formal. Com esse objetivo, foi produzida, no decurso deste artigo, uma reflexão a fim de avaliar o posicionamento da família na educação dos filhos perante os desafios impostos pelo capitalismo; e, nas últimas décadas, pelo neoliberalismo. Foram efetuadas pesquisas para fins de complementação dos argumentos usados por Bourdieu em sua obra. A escolha do tema justifica-se em função das inúmeras explicações e argumentações sobre as consequências do que vem ocorrendo na educação no Brasil, frente as imposições do sistema financeiro. A nosso ver, há um posicionamento governamental no sentido de adotar dispositivos legais para atender as demandas impostas pelo referido sistema, o que trouxe consequências cujo viés mais penoso é não admitir que a educação seja a mola propulsora do desenvolvimento de uma nação.

Palavras-chave: Capital cultural. Educação. Universalização educacional.

\section{INTRODUÇÃO}

Visando contribuir socialmente com seus conhecimentos, Bourdieu deu forma aos seus pensamentos e entendimentos sobre educação, bem como, com os fatores que contribuem com o sucesso do processo educativo e fez vários questionamentos sobre esse tema, o que torna mais verídicos aos leitores e a população em geral a nossa situação frente aos desafios impostos aos processos de ensino. É preciso esse tipo de reflexão, uma vez que, a sociedade credita somente à escola os motivos do insucesso dos educandos ao longo de sua carreira estudantil, e se esconder através de acontecimentos inoportunos para represar as crises advindas de um processo onde a família tem papel de extrema relevância para o sucesso acadêmico dos seus.

\footnotetext{
${ }^{\text {I }}$ Possui graduação em Geografia pela Universidade Estadual de Goiás (200I). Atualmente é Professor da Secretaria da Educação de Goiás. Tem experiência na área de Geografia. Mestrando em Educação pelo PPGE - FACMAIS - Inhumas - GO.
} 
Este artigo está planeado sobre os conceitos educativos e sociais que se encontram presentes na obra de Bourdieu, há também um acoplamento de hipóteses de outros autores para confrontar tais argumentos e desenvolver uma linha de raciocínio com maior embasamento científico possível. Este entroncamento de referências proporcionou um vasto referencial bibliográfico e permitiu obter uma maior reflexão sobre o tema proposto.

Ao confrontar as ideias de Bourdieu com outros pesquisadores do nosso tempo e com os desafios impostos à educação a partir do século XXI, encontraremos respaldo para suas ideias e através dessas mesmas ideias encontraremos também a explicação e justificativa para os problemas que permeiam a educação, sobretudo a partir da universalização do ensino que no Brasil tem contornos sociais gravíssimos. Além disso, o artigo preocupou-se em apresentar as lutas de classes e os interesses econômicos que têm pautado a educação brasileira bem como os projetos, os programas e a legislação educacional que acabam por constituir uma prova material da existência de lutas sociais.

Esse pressuposto de luta de classes e o ideal de universalização do ensino público gratuito fez aflorar no ceio da sociedade brasileira um novo confronto social, já que todos terão acesso aos sistemas de ensino, por direito e por força da lei, é preciso que sejam encontradas novas formar para a manutenção do privilégio das classes dominantes. Com o intuito de fundamentar esta pesquisa, partiu-se primeiramente da necessidade de se obter um conhecimento sobre os impactos advindos da política neoliberal e de suas peculiaridades que têm alterado os rumos da educação tanto socialmente quanto economicamente. Além disso, o trabalho se preocupa em apresentar argumentos sobre os impactos sociais advindos das recomendações feitas por organismos internacionais que atuam ditando as metas para os países em desenvolvimento. Devido a este fato, o problema de pesquisa desse trabalho busca responder a seguinte pergunta: como aplicar a teoria dos capitais no processo de ensino frente às imposições do neoliberalismo?

Essa investigação tem como objetivo geral estudar os argumentos de Bourdieu e dialogá-los com o pensamento de outros estudiosos e historiadores, trazendo uma reflexão no confronto bibliográfico sobre a situação existente no Brasil. Seguindo este 

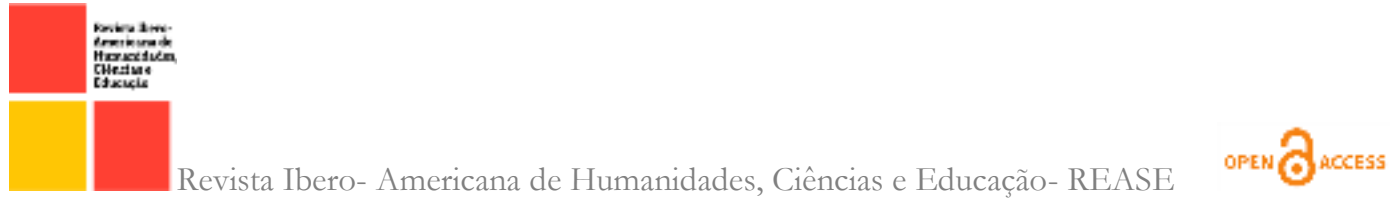

preceito, os objetivos específicos são: avaliar os principais impactos do neoliberalismo nas questões sociais e destas sobre os processos educacionais;

\section{CONTEXTO CULTURAL}

Bourdieu não vê os indivíduos como seres autônomos, para ele, existem um conjunto de forças produzidas socialmente que atuam sobre os indivíduos determinando suas ações a partir do que ele chama de habitus, este por sua vez reflete as características sociais de onde o indivíduo está inserido, elaborando a partir dele sua trajetória e assegurando sua reprodução social (FERREIRA, 2013 P. 48). Independentemente da realidade social na qual estão inseridos, uma vez dentro dela os indivíduos lutam pelo controle dos bens produzidos, considerando que cada sociedade a seu tempo enfrenta diferentes desafios fica fácil compreender que quem estiver melhor preparado enfrentará com sucesso esses desafios terá maior controle não só sobre os bens, mas também sobre a sociedade geral.

Nesta lógica de domínio o pesquisador destaca a importância dos padrões culturais - estes são divididos em dois grupos - padrões culturais superiores e padrões sociais inferiores, vejamos:

[...] distingue-se entre alta e baixa cultura, entre religiosidade e superstição, entre conhecimento científico e crença popular, entre língua culta e falar popular. (NOGUEIRA \& NOGUEIRA, 2004 P. 33)

Assim, tanto indivíduos, quanto instituições que representam a cultura dominante buscam manter sua privilegiada posição, para tanto, apresentam seus bens e produção como se estes fossem superiores aos demais. Para Bourdieu isso se constitui numa forma de violência, já que há a imposição da cultura de um grupo sobre os demais indivíduos. Se prevalece os interesses de um grupo geralmente minoritário sobre uma maioria, a questão que podemos levantar é sobre a postura dos dominados culturalmente frente a esta realidade, e sobre isso Bourdieu explica que há duas possibilidades de posicionamento, uma de aceitação e outra de subversão ou contestação. Frente a estas possibilidades, o que é mais provável acontecer é que estes indivíduos cujos padrões culturais são considerados inferiores se convertam à cultura dominante, ato que Bourdieu chama de boa vontade cultural. 
No conjunto da sociedade essa dominação acaba por não ser percebida pela maioria dos indivíduos e acaba por se tornar legitima já que foi historicamente imposta pelos grupos dominantes. O caráter arbitrário da cultura dominante acaba por não sendo percebido nem entre os dominantes, tão pouco entre os dominados, vejamos o que observa Maria Alice Nogueira e Carlos Nogueira sobre esta questão:

\begin{abstract}
Os primeiros seriam socializados na cultura dominante e, portanto, aprenderiam, desde muito cedo, a toma-la como naturalmente válida. Eles não se apegariam a essa forma de cultura cinicamente, apenas por se tratar da cultura dominante, mas pelo fato de terem sido criados no interior dela. Os demais, embora não tenham sido socializados na cultura dominante e, por isso, não sejam capazes de se apropriar plenamente dessa, aprenderiam a reconhecê-la e a valorizá-la. (Nogueira e Nogueira, apud Bourdieu, 2004 p.34)
\end{abstract}

A partir dessa ideia é possível perceber como a hierarquia cultural contribui para reforçar, reproduzir e legitimar a hierarquia social que acaba se naturalizando. No entanto, é mais complexo compreender os reais interesses envolvidos nesse processo.

\title{
2.I Capital cultural
}

Compreendido essa forma de estruturação da sociedade em grupos sociais marcados por papeis de dominação e dominados e desejando romper com essa estrutura é preciso construir caminhos que nos conduzam a uma sociedade livre dessas mazelas e o processo educativo é importante via capaz de promover a libertação dessa dominação ou pelo menos promover a tomada de consciência de tal realidade. Claro que ter consciência de uma realidade não representa a certeza de liberdade, pois existe um conjunto de forças exercidas por determinado grupo para que tal realidade seja mantida ou que parte dos interesses sejam preservados e desta forma possam manter os privilégios.

Assim, enquanto um grupo se vale da educação para fins de libertação, outro grupo se utiliza da mesma como forma de manter-se como classe dominante. Bourdieu talvez tenha sido o sociólogo que melhor sintetizou os bens culturais de maior impacto na educação, por analogia ao capital econômico, cunhou o termo capital cultural e mostrou como esse tipo de capital favorece quem o possui. Por capital cultural podemos entender por exemplo, o domínio da língua culta, atrelado ao capital literário proporciona aos indivíduos a capacidade de produzir, reconhecer, apreciar e consumir 
esses bens culturais, portanto, teriam maior facilidade de alcançar ou manter-se nas posições mais altas da estrutura social.

Como estamos inseridos em um regime capitalista, segundo Bourdieu os dois tipos de capital de maior importância nestas sociedades são o capital cultural e o capital econômico, assim, a posição que o indivíduo ocupa na sociedade está intimamente ligada ao volume de capital que o indivíduo possui, sendo possível inclusive agrupa-los de acordo com esse volume de capital, que também serve de parâmetro para a relação dominantes e dominados.

Para resolver a equação - muito capital econômico e pouco capital cultural - ou pouco capital econômico e muito capital cultural - ou - pouco dos dois - e finalmente muito dos dois, e fazer uma análise mais fina, Bourdieu considera outros dois tipos de capitais, o capital social e o capital simbólico. O capital social pode ser entendido como o conjunto de relações sociais que o indivíduo mantém, ele é capaz de gerar benefícios materiais ou simbólicos - prestígio. Já o capital simbólico refere-se ao prestígio que o indivíduo goza na sociedade na qual está inserido.

Considerando o universo escolar como uma forma de mercado onde se emprega um certo volume de recursos, sobretudo, capital cultural, obtendo em função disso um retorno na forma de sucesso escolar - diplomas, agregando em função destes novos instrumentos de acumulação. Quando maior o volume possuído e investido, maiores as possibilidades de ter um bom retorno.

Considerando o sucesso acadêmico como resultado do volume de capital investido, o que poderíamos dizer da educação brasileira frente ao projeto de universalização do ensino nas escolas públicas? Como construir e implementar um projeto educacional de sucesso em comunidades de parco capital cultural?

É notável a contribuição dos franceses sobre a educação, assim como Bourdieu, Émile Durkheim, escrevendo obre o ensino secundário naquele pais afirmou:

Costuma-se fazer queixas das variações por demais frequentes que ocorreram nos programas, nos últimos vinte anos, e culpa-se ocasionalmente essas mudanças por demais repetidas pela crise atualmente vivida pelo ensino secundário. Vê-se que essa instabilidade não data de ontem; que não é imputável a tais personalidades ou a tais circunstâncias particulares, mas sim que configura um estado crônico, que dura há um século, e depende evidentemente de causas impessoais. Longe de ser a causa do mal, é seu efeito e indício exterior; revela-o mais do que o produz. [...] Acredita-se que, para 
restabelecer nosso ensino secundário em bases sólidas, bastariam algumas felizes mudanças de detalhe, bastaria encontrar uma melhor dosagem das disciplinas ensinadas, aumentar a parte das letras ou das ciências, ou equilibrálas engenhosamente, quando o necessário, na verdade, é uma mudança de espírito e orientação (DURKHEIM, 1995, p. 287-288).

Claro que Bourdieu está tratando da influência do capital humano no sucesso acadêmico dos indivíduos e Durkheim fala da crise do sistema educacional. No Brasil diversos pesquisadores se dedicam a pesquisar tanto Bourdieu quanto Durkheim, já que ambos tratam aqui do mesmo elemento - a educação.

Para ARANHA e SOUZA (2013), a crise da educação contemporânea no Brasil se agrava a partir de I960 com a transformação midiática, para eles:

O problema é que o clima de agitação cultural e a grande transformação midiática que marcaram o mundo ocidental a partir dos anos i96o retiraram da escola o locus da aprendizagem e solaparam as bases sobre as quais se sustentavam os professores para levar adiante o ofício da docência. Foi essa quebra brusca tanto da instituição como locus fundamental da produção e difusão do conhecimento moderno quanto do profissional que ali atuava como seu principal agente que instaurou essa crise que se arrasta até nossos dias.

(ARANHA \& SOUZA, Educar em Revista, 2013 p. 75-76)

Como se sabe, o "paradigma da reprodução" foi constituído por um conjunto de teorias sociológicas da educação que se desenvolveram, principalmente na França, a partir dos anos 196o, e que traziam uma nova explicação sobre a relação entre escola e sociedade. Entendendo que a escola tem funcionado mais como um mecanismo de reprodução social do que produzindo novas relações sociais, recai sobre ela essa crítica, contrariando a expectativa que se tinha sobre ela. (ARANHA d SOUZA, apud Souza 2013). Pierre Bourdieu e Claude Passeron (1992) denunciaram-na como espaço de reprodução da cultura dominante, pairando sobre o ambiente escolar a crítica das ciências sociais sobre o processo de ensino e sua ação sobre as relações sociais.

No Brasil, nas últimas décadas, sob a retórica de qualidade e crise da educação estão sendo implementados projetos educacionais que culminam em reformas do ensino, estas reformas decorrem do conjunto de mutações políticas, econômicas e culturais ocorridas na maioria dos países ocidentais, seu maior impacto na educação tem sido aquele decorrente da massificação que é fruto da universalização da escola.

(NOGUEIRA, Cadernos de Pesquisa, 2021, p. 8)

Para Maria Alice, pesquisadora de Bourdieu no Brasil ao tratar dos efeitos da massificação e do capital cultural sobre a educação, observou:

É que a chegada de "novos públicos" - em um sistema anteriormente reservado a determinados grupos sociais - traz consigo novos repertórios culturais derivados da cultura popular, da indústria cultural, das culturas juvenis, levando a expressivas mudanças nos padrões curriculares. NOGUEIRA, Cadernos de Pesquisa, 202I, p. 8)

Dentre as alterações curriculares mais importantes, três são destacadas por Maria Alice, a saber: 
a. A emergência de novas linguagens a exemplo da cultura eletrônico-digital que costumamos opor à cultura escolar tradicional, apontando essa última como fonte de desmotivação e de dispersão dos alunos.

b. O imperativo do multilinguismo, ou seja, as exigências impostas - em uma era de globalização, tanto pelos novos estilos de vida quanto pelo mercado de trabalho - do domínio de idiomas e de certas competências em matéria de comunicação.

c. A necessidade, em nome da empregabilidade, do desenvolvimento de disposições cosmopolitas favorecedoras da mobilidade geográfica. Trata-se de desenvolver aquilo que Murphy-Lejeune (2003) denomina de "capital de mobilidade", que engloba traços de personalidade como autonomia, abertura, adaptabilidade, tolerância à alteridade, demandados daqueles que se destinam a serem "cidadãos do mundo", para usar uma metáfora tão cara ao senso comum e tão presente no discurso das famílias (Nogueira \& Aguiar, 2008).

Essas mudanças têm levado a novas mudanças da escola e novos conteúdos, assim como, novos capitais culturais e nova legislação capaz de moldar a educação aos interesses do capital e das classes dominantes.

\subsection{Adaptação da educação aos interesses do sistema financeiro internacional}

Outra pesquisadora que avalia os impactos do sistema neoliberal sobre a educação é Marilena Chauí, nos últimos anos ela tem alertado para os impactos que essa adaptação da educação os interesses dos sistemas capitalista e neoliberal tem causado sobre a vida dos estudantes, sobretudo aqueles oriundos das camadas sociais menos favorecidas e que frequentam as escolas públicas. Este alerta é confirmado através da avaliação feita por Saviani em seu artigo Políticas educacionais em tempos de golpe: retrocessos e formas de resistência. Saviani nos dá uma síntese do que se pode verificar como resultado das últimas políticas educacionais em curso no Brasil, vejamos:

O resultado observável empiricamente é a precarização geral da educação em todo o país é visível na rede física, nos equipamentos, nas condições de trabalho e salários dos profissionais da educação, nas teorias pedagógicas de ensino e aprendizagem, nos currículos e na avaliação dos resultados. (SAVIANI, 2020, p. 4)

Mais que um discurso, a ideologia da competência dos modernos administradores neoliberais esconde, em verdade, um ataque feroz às universidades públicas e, em sentido mais amplo, às tentativas de democratização das relações sociais no interior da estrutura social do Brasil. Consequentemente, acentua a polarização entre carência e privilégio a partir da destruição das instituições públicas que poderiam mediatizar a criação de novos direitos pelos sujeitos sociais. 
Essas observações feitas por Marilena Chauí irão reverberar naquilo que Frigotto diz ao avaliar o modelo de educação implantado no Brasil nos anos 9o. Para ele, as forças que protagonizaram o ajuste estrutural daquela década foi o núcleo dominante da minoria prepotente. Vejamos:

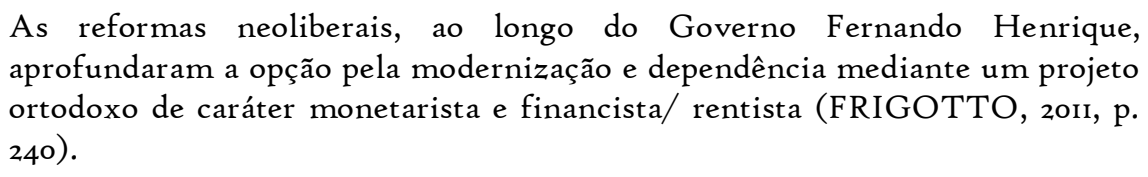

As reformas neoliberais, ao longo do Governo Fernando Henrique, aprofundaram a opção pela modernização e dependência mediante um projeto ortodoxo de caráter monetarista e financista/ rentista (FRIGOTTO, 2oII, p. 240).

Nossa luta contra o neoliberalismo é a garantia de que a reconstrução da escola pública, laica e universal em seus três níveis é possível, pois o que está em curso não segue uma lei natural, tão pouco é uma catástrofe natural, é uma ideologia de uma forma histórica particular assumida pela acumulação do capital. Portanto, se é algo histórico, é algo que os homens fazem em condições determinadas, ainda que não o saibam e que podem deixar de fazer se tomarem consciência dessas condições e decidirem se organizar contra elas.

Nessa perspectiva, pensamos que o desafio maior é antes de tudo descontruir o que foi naturalizado acerca do papel dos jovens cuja origem remonta às classes trabalhadoras. Destaquemos ainda que é preciso que o jovem compreenda que seu futuro não foi traçado na maternidade como deseja a classe dominante. Se fosse assim, não haveria possibilidade de mudança, somente uma reprodução social.

Outra questão analisada por Marilena é como o neoliberalismo age sobre os meios de comunicação (mídias) a fim de criar uma fragmentação econômico-social e uma compressão espaço temporal gerada pelas novas tecnologias e pelo percurso do capital financeiro. $O$ imaginário instituído pela grande mídia nacional não reflete a cultura nacional-popular, reflete e inculca a mentalidade senhorial das poucas famílias que detém o controle da indústria cultural no Brasil. Marilena passa da investigação da subjetividade pós-moderna, formada pela indústria cultural, à interrogação das transformações no corpo próprio como sujeito da percepção.

\subsection{Vulnerabilidade da educacional}

Como esses organismos financeiros internacionais não podem atuar diretamente sobre a educação no país, a forma de conseguir fazê-lo é influenciar através de pacotes a 

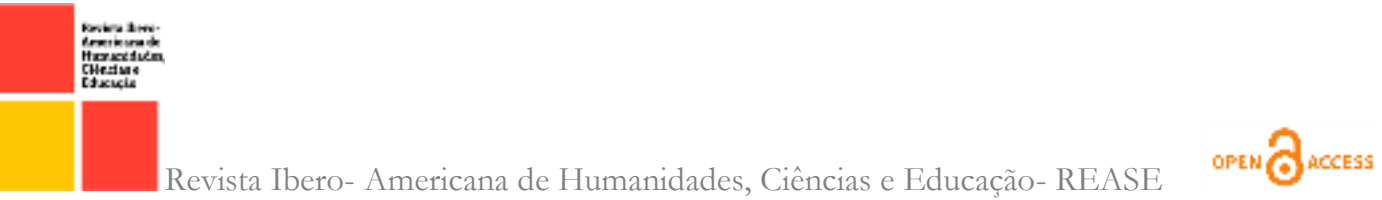

política educacional do país. Para que isso tenha aceitação entre as diferentes camadas sociais, é necessário criar um discurso cuja pauta central consista em desqualificar o que está sendo feito. Isto é feito através da política de resultados, sem levar em conta as condições físicas e financeiras da escola, assim como não levam em conta a falta de materiais didáticos e recursos humanos; não consideram também as condições de trabalho dos profissionais da educação, as subjetividades dos alunos, entre outras questões de fundamental importância em todo processo educacional.

O diagnóstico usa dois critérios: custo/benefício e a lógica da punição/recompensa. Esta é uma lógica financeira que, se aplicada aos sistemas de ensino, acaba por tratar os estudantes como produto e os professores como operários. Essa situação apresentada sem uma contextualização acaba justificando a necessidade de reforma no sistema de ensino, ao nosso ver, o problema não é a reforma e sim o tipo de reforma proposta, a quem ela interessa e quais os impactos dela para as camadas sociais mais baixas.

Como se vê, o neoliberalismo fragmentou o mundo do trabalho e a sociedade; deu ao mercado a chave da suposta racionalidade do mundo e fez da competição individual a condição da existência bem ou mal sucedida fortalecendo a divisão social entre os que supostamente sabem e devem mandar e os que não sabem e por isso devem obedecer; introduziu também o desemprego estrutural e a divisão entre a opulência e a miséria jamais vistas.

\section{4 - Ideologia da competência}

A ideologia burguesa era um pensamento e um discurso de caráter legislador, ético e pedagógico que definia para toda a sociedade o verdadeiro e o falso, o bom e o mau, o lícito e o ilícito, o justo e o injusto, o normal e o patológico, o belo e o feio, a civilização e a barbárie. Esse discurso muda a partir de 1930 como efeito direto do processo social do trabalho e das relações sociais. Assim o trabalho industrial passaria a seguir o padrão fordista e com ele é introduzia uma nova prática das relações sociais conhecida como a Organização. A maneira como o modelo da Organização se difunde e 
se espalha por todas as instituições sociais e por todas as relações sociais é o que Lefort chama de ideologia contemporânea ou ideologia invisível (cf. CHAUI, 2014, p. 167).

Esse modelo de Organização que parece emanar do seio social como algo natural, possui algumas características que trouxeram novos paradigmas para as relações sociais; dentre elas, a afirmação de que organizar é administrar, e administrar é introduzir racionalidade nas relações sociais; outra característica é a afirmação de que uma organização será racional se for eficiente e será eficiente se estabelecer uma rígida hierarquia de cargos e funções; e, finalmente, vemos a ideia de que uma organização é uma administração científica racional que possui lógica própria e funciona por si mesma independentemente da vontade e da decisão de seus membros. Com isso, a divisão social do trabalho faz-se pela separação entre os que têm competência para dirigir e os incompetentes, que só sabem executar. Vejamos o que diz Lefort:

\footnotetext{
A divisão social se realiza entre os competentes (os especialistas que possuem conhecimentos científicos e tecnológicos) e os incompetentes (os que executam as tarefas comandadas pelos especialistas). A ideologia da competência realiza a dominação pelo descomunal prestígio e poder do conhecimento científico-tecnológico, ou seja, pelo prestígio e poder das ideias científicas e tecnológicas (LEFORT apud CHAUI, 20I4, p.48).
}

Daí vem a ideia do discurso competente: um discurso que defende, mas oculta que é feito para quem ocupa um lugar determinado na hierarquia organizacional. Noutras palavras, o discurso competente, em dado momento, invalida os sujeitos; em outro, tenta revalidá-los, mas agora como indivíduos privados, destituídos do sentimento de pertencimento - a chamada competência privatizada.

Lembremos que há dois aspectos hoje indissociáveis no modo de produção capitalista: o discurso da Organização afirma que só existe racionalidade nas leis do mercado; o discurso do especialista afirma que só há felicidade na competição e no sucesso de quem vence. Isso cria a competição entre indivíduos, razão do sucesso de alguns deles contra os demais. Com isso, a educação além de oferecer o diploma está com a responsabilidade de oferecer a quem a frequenta um conjunto de ideologias que visem a manutenção dos interesses das elites dominantes - via interesses empresariais despojando-se da sua função de oferecer formação crítica, de pesquisa de igual teor e relevância social. 

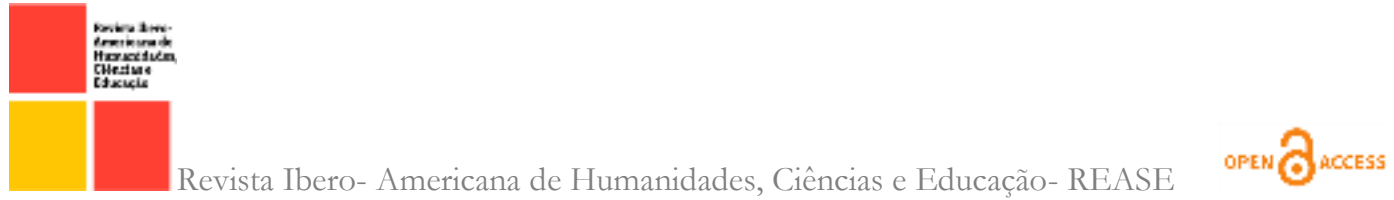

\section{5 - Reforma educacional}

A ideia de reforma da educação abrange os diferentes níveis de ensino e tem objetivos escusos que passam pela destruição do papel do Estado. Isso se torna cada vez mais visível pelo menos em dois aspectos: primeiramente, a massificação do ensino, alguns aspectos devem ser enumerados, dentre eles o número cada vez maior de alunos ingressando na universidade; por outro lado, a degradação cada vez maior do ensino médio, prevalecendo os aspectos quantitativos sobre os qualitativos. Aqui temos claramente uma maior competitividade entre aqueles que ali conseguem se inserir, criando uma espécie de pódio escolar (Draelants 2014). O outro aspecto refere-se à gestão do Ministério da Educação que tem colocado as questões do ensino público sob a tutela do Ministério do Planejamento. Com isso, é possível traçar um novo perfil do ensino no Brasil ficando claro que este é posto a serviço de ideias que estão enraizadas em nossa sociedade desde a ditadura militar. Assim vemos na noção de segurança, que tem um papel ideológico; também na de desenvolvimento econômico e de integração; estes determinariam a forma, o conteúdo, a duração, a quantidade e a qualidade de todo o processo educacional - do primeiro grau à universidade, vemos portanto que esse posicionamento político, a orientação dita neoliberal, dos anos 1980 e 1990, de desregulamentação e de encolhimento do Estado, resultou em reformas dos serviços públicos com ênfase no mercado e na livre escolha por parte dos sujeitos usuários.

Para Saviani, essas reformas são feitas no improviso. Na medida em que surgem demandas importantes para a educação, a solução encontrada é uma emenda constitucional, lei, decreto ou portaria sem atentar para a real necessidade ou elo de ligação com outras medidas de efeito equivalentes. Sob o resultado de tais medidas, observemos o que ele diz:

O resultado observável empiricamente é a precarização geral da educação em todo o País visível na rede física, nos equipamentos, nas condições de trabalho e salários dos profissionais da educação, nas teorias pedagógicas de ensino e aprendizagem, nos currículos e na avaliação dos resultados (SAVIANI, 2020, p. 4).

Se a situação é marcada pelo improviso, o que se verifica agora, depois do acontecido em 2016, se constituí num verdadeiro retrocesso do pouco que havíamos conseguido avançar na primeira década do século XXI. 
Sobre a primeira década do século XXI Gaudêncio Frigotto afirma:

No plano das políticas educacionais, da educação básica à pós-graduação, resulta, paradoxalmente, que as concepções e práticas educacionais vigentes na década de 1990 definem dominantemente a primeira década do século XXI, afirmando as parcerias do público e privado, ampliando a dualidade estrutural da educação e penetrando, de forma ampla, mormente nas instituições educativas públicas, mas não só, e na educação básica, abrangendo desde o conteúdo do conhecimento até os métodos de sua produção ou socialização (FRIGOTTO, 2011, p.242).

As avaliações feitas por Saviani e Frigotto sobre a primeira década do século XXI dão cabo ao que Marilena alertava que aconteceria com a educação brasileira. A questão agora gira em torno de como iremos conseguir nos organizarmos para lutar contra o que está em curso na educação brasileira.

\section{CONCLUSÃO}

O desenvolvimento do presente artigo contribui para a compreensão do quão impactante é o sistema financeiro sobre a educação brasileira, além de desenvolver um paralelo de argumentos em que se mostra que o sistema neoliberal é a fonte dos problemas no campo da educação e da cultura e, ao mesmo, tempo razão do agravamento destes, uma vez que as camadas sociais segregadas são as que mais sofrem com os efeitos das reformas recomendadas pelos organismos econômicos internacionais que atuam sobre o governo.

Para os pais de alunos, trata-se agora de oferecer aos filhos as melhores oportunidades de êxito, de preferência nos setores mais prestigiosos do sistema de ensino. Eles o farão mediante o emprego de estratégias diversificadas e cada vez mais sofisticadas, dentre as quais são destacadas:

a. As condutas de escolha do estabelecimento de ensino para os filhos. Em seu ato de escolha, os pais investirão, crescentemente, um capital de informações variadas sobre o funcionamento do sistema escolar (resultados exibidos em avaliações sistêmicas, rankings de estabelecimentos publicados na mídia, mas também as chamadas informações "quentes" obtidas em suas redes de relacionamentos, por exemplo), ampliando assim sua habilidade de distinguir entre os diferentes tipos de estabelecimentos de ensino e, no caso dos mais habilitados, até mesmo ajustá-los ao perfil escolar do filho (mais ou menos estudioso, esforçado, etc.).

b. As estratégias de intensivo monitoramento da vida escolar dos filhos, que vão do controle das atividades dos profissionais do ensino e da participação nas instâncias administrativas da escola à ajuda doméstica nos deveres de casa e demais atividades requeridas pela escola. Para isso, os pais de alunos na atualidade não poupam esforços e dispendem tempo e energia em prol do desempenho escolar da prole. Revisitando rapidamente, à luz do cenário atual, 
a tese bourdieusiana do impacto inexorável (e "osmótico") do capital cultural familiar sobre o sucesso escolar, Meuret (20II) escreve que "as mães burguesas de hoje perdem mais tempo cobrando empenho escolar de suas crianças do que as levando ao teatro". Para ele, "o suor exerce uma função que, sem dúvida, Bourdieu e Passeron já subestimavam, mas que posteriormente aumentou” (p. 460).

c. O recurso a um arsenal de dispositivos (onerosos) de suporte à ação da escola que têm por finalidade municiar o aluno para a "corrida de obstáculos" escolar. Trata-se de um conjunto constituído de materiais paraescolares e de dispositivos de terceirização da ajuda aos pais (aulas particulares, aulas de idiomas e de artes, consultórios de psicopedagogia, empresas especializadas no reforço escolar e no acompanhamento do dever de casa, sessões de coaching, etc.) que Glasman (20II) chamou de uma "escola fora da escola". Essa programação intensa e contínua que estrutura o tempo extraescolar tem sido tematizada, na pesquisa educacional, sob a expressão de shadow education (Bray, 2009), por ocorrer à sombra do sistema de ensino.

d. O crescente apelo a estratégias de internacionalização da trajetória escolar dos filhos, geralmente por meio dos intercâmbios no exterior que hoje abrangem todos os graus do ensino. Embora o ensino superior continue sendo o nível de ensino mais internacionalizado, verificam-se atualmente estratégias familiares muito precoces de internacionalização que implicam em escolha de pré-escolas e escolas primárias e secundárias bilíngues ou multilíngues. Tais intercâmbios se fazem, em sua larga maioria, em direção aos países desenvolvidos e de língua inglesa, como num "tropismo" (Nogueira, apd, Darchy-Koechlin \& Van Zanten, 2005).

Em suma, tudo leva a crer que - apesar de seu "viés de baixa" - o papel do

capital cultural continua sendo decisivo no contexto atual, desde que concebido em seu sentido amplo, que incorpora as novas dinâmicas culturais em curso e a importante mobilização parental contemporânea em favor da transmissão da herança cultural.

\section{REFERÊNCIAS}

BALL, S. J. Currículo sem Fronteiras, v.I, n.2, pp.99-II6, Jul/Dez 200I

CHAUI, Marilena. A ideologia da competência / Marilena Chaui ; organizador André Rocha. -- Belo Horizonte : Autêntica Editora; São Paulo: Editora Fundação Perseu Abramo, 2014. (Escritos de Marilena Chaui, 3)

FERREIRA, Wallace. BOURDIEU E EDUCAÇÃO: CONCEPÇÃO CRÍTICA PARA PENSAR AS DESIGUALDADES SOCIOEDUCACIONAIS NO BRASIL. Revista multidisciplinar de Ensino, Pesquisa, Extensão e Cultura Cap-UERJ, V 2, n 3. P. 46-59, 2013.

FRIGOTTO, Gaudêncio. Revista Brasileira de Educação v. I6 n. 46 jan.|abr. 20 II

NOGUEIRA, Maria Alice. Bourdieu \& a educação/ Maria Alice Nogueira, Cláudio M. Martins Nogueira - 4 ed; 2 reimp. - Belo Horizonte: Autentica Editora, 2017. 
NOGUEIRA, Maria Alice. O CAPITAL CULTURAL E A PRODUÇÃO DAS

DESIGUALDADES ESCOLARES CONTEMPORÂNEAS. Cad. Pesqui., São Paulo, V.5I, P. I-I3, 2021.

SAVIANI, Dermeval. Roteiro, Joaçaba, v. 45, p. I-18, jan./dez. 2020 | e21512 |E-ISSN 2177-6059 